\title{
PENERAPAN KEAMANAN KEUANGAN DALAM APLIKASI E-MONEY
}

\author{
Reynanda S.Brahmana \\ Universitas Islam Negeri Sumatera Utara \\ Rey19nanda@gmail.com \\ Muhammad Irwan Padli Nasution \\ Universitas Islam Negeri Sumatera Utara \\ irwannst@uinsu.ac.id
}

\begin{abstract}
E-MONEY is electronic money that can be accessed through the application and also as a payment instrument that uses electronic media. The difference is also striking with conventional money in the sense of the money we store in our wallet that distinguishes it is its flexibility and accessibility. This is because the base of E-Money transactions uses a system that is connected online and without having to bring together people who transact. But the beginning of the establishment of the E-Money application today has not received much response from the public because of the security system that makes customers doubt the application. With the advancement in technology, the application continues to improve its security system so that customers who want to use the application can feel safe. Companies such as food, fashion, etc. they intensively collaborate with applications that can offer attractive products such as holding discounts, cashback so that their products are much more desirable. Besides e-money applications can now pay such as electricity bills, pay BPJS, buy credit and many others while the party is working with the application. The e-money application can also be transferred between banks so customers can be more effective and efficient without having to go far to the bank. This is very beneficial for customers and also customers can be far more efficient.
\end{abstract}

Keywords: E-money application, Security system

\section{PENDAHULUAN}

Perkembangan teknologi di zaman sekarang memberikan kemudahan bagi masyarakat dalam memenuhi kebutuhan hidupnya maupun kebutuhan orang disekitarnya. Pada era digital, masyarakat dituntut untuk lebih aktif berteknologi karena di era teknologi ini mendorong masyarakat untuk melakukan berbagai kegiatan dan juga bertransaksi secara online. Perkembangan E-Money sendiri dimulai sejak 1960 di luar negeri. Perkembangan di indonesia sendiri mulai berkembang setiap tahunnya penggunaan EMoney semakin meningkat. Menjadi semakin populer karena pengusaha bertransaksi melalui aplikasi E-Money tersebut. Bahkan, fasilitas-fasilitas umum telah memperkenalkan aplikasi E-Money ini sebagai pembayaran tol, commuterline, dan banyak lagi bahkan banyak bank atau perusahaan lainnya yang menyediakan jasa E-Money untuk memudahkan nasabahnya agar kegiatan nasabah dapat dilakukan dirumah tanpa harus mendatangi tempat transaksinya. Misalnya di tahun 2013 transaksi mencapai Rp 6,7 Miliar per hari atau Rp 2 Triliun per tahun.

Walaupun penggunaan aplikasi E-Money sedang populer tapi masih banyak masyarakat belum mengerti atau belum memiliki aplikasi E- Money ini karena mereka beranggapan jauh lebih aman kalau melakukan transaksi onfline. Pengguna yang paling antusias menggunakan aplikasi ini biasanya kebanyaakan yang memiliki ponsel dan penggunanya biasanya memiliki umur yang muda karena jauh lebih mudah dan tidak perlu jauh jauh bertransaksi serta masyarakat yang di kota-kota besar karena 
lebih praktis saat bertransaksi. Salah satu penyebab engganya orang menggunakan aplikasi e-money ini biasanya memiliki keraguan saat menggunakannya karena mereka masih takut dengan keamanan yang dimiliki aplikasi dan biasanya keraguan juga muncul karena kasus-kasus yang berkaitan dengan sistem keamanan aplikasi e-money itu sendiri.

Setelah kepopuleran e-money kian melonjak dan semakin dikenal masyarakat luas. Banyak perusahaan startup yang mulai membangun bisnis dalam bidang keuangan atau biasa disebut fintech inilah asal mula dikeluarkannya produk dompet digital atau yang sudah kita kenal dengan sebutan e- wallet hanya dengan koneksi internet sistem e-wallet ini sudah bisa digunakan oleh para konsumen hal ini menjadi lebih efektif dan efesien karena tidak perlu ke mesin atm atau mobile banking untuk melakukan transaksi pembayaran

Penggunaan E-Money pada saat akan diprediksi akan terus meningkat seiring kemajuan teknologi walaupun transaksi manual akan terus ada. Sebab penggunaan E-Money tidak memakan waktu yang lama dan tidak harus lelah pergi ke tempat tujuan kita bertransaksi. Data di bawah ini menunjukkan kalau di tahun 2018 saja pengguna melonjak mencapai $209,8 \%$

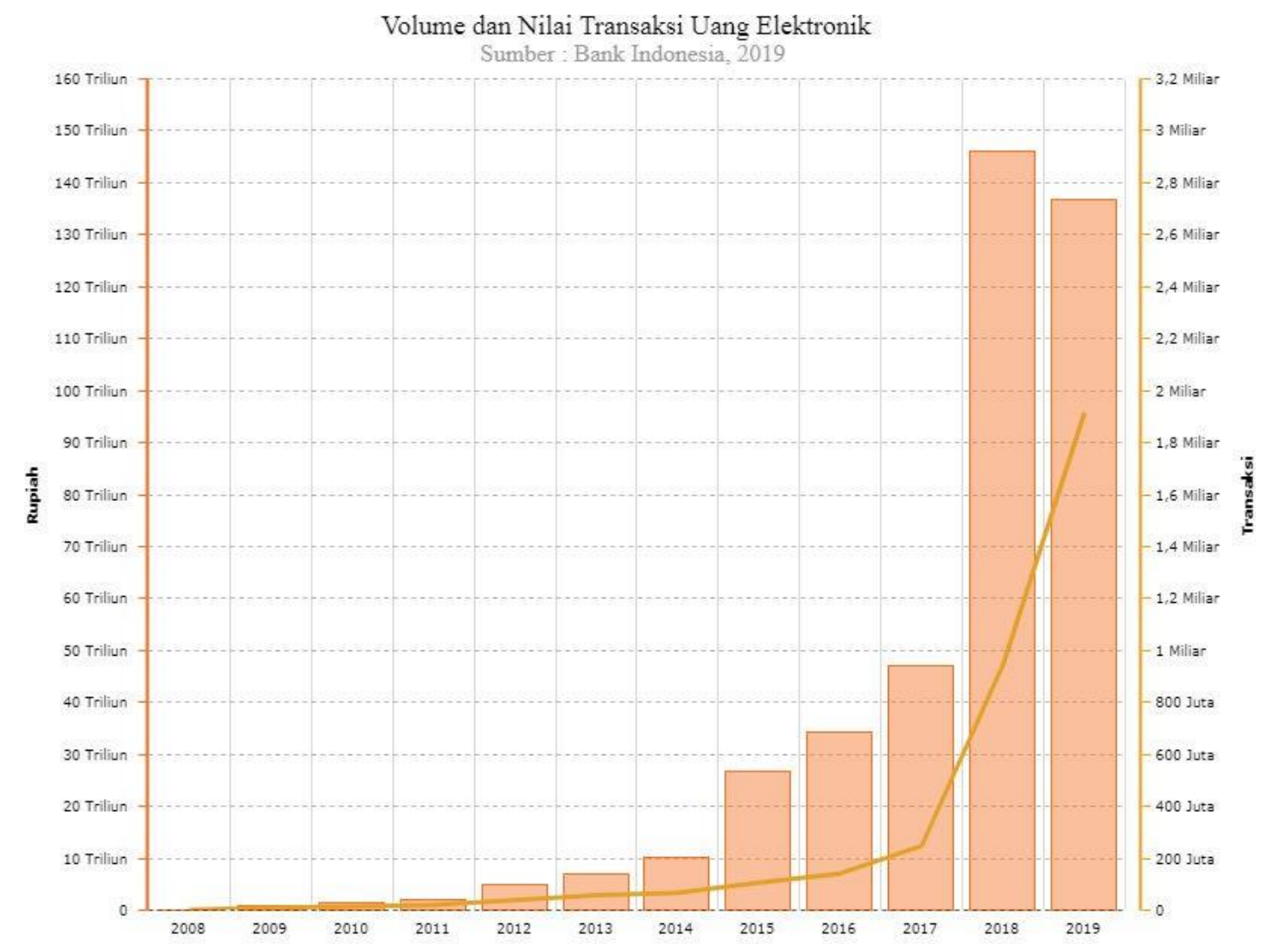

Sumber: Bank Indonesia, 2019 


\section{CARA KERJA E-MONEY}

Penggunaan e-money ini tidak memerlukan adanya proses otoritas seperti halnya pemakaian pin atau tanda tangan, karena e-money tidak berkaitan langsung dengan rekening nasabah yang ada di bank. Penggunaan e-money tidak membebankan pembayarannya pada rekening bank, seperti halnya kartu kredit atau kartu debit. Nasabah hanya perlu mentop-up kan saldonya di merchant yang telah bekerja sama dengan aplikasinya ataupun bisa dengan top up di bank.

Selain itu pengguna aplikasi e-money hanya perlu menscan kode yang ada di tempat kita bertansaksi ataupun mengirim saldo dengan rekening yang mau kita tujukan. Dengan begitu cara yang dipakai sangat memudahkan kita tanpa harus mengantri seperti halnya kita melakukan transaksi offline.

Manfaat dari aplikasi e-money yaitu memberikan kemudahan, kecepatan dan kepraktisan dalam melakukan berbagai transaksi pembayaran. Sehingga kita tidak perlu menyiapkan uang tunai untuk pembayaran, kita juga tidak perlu menerima uang kembalian karena kita hanya mengeluarkan uang sesuai transaksi kita, terdapat database yang dapat mencatat selama kita melakukan transaksi jadi kita tidak susah mengingat transaksi kita, dan juga bisa membayar kartu tol yang sekarang menggunakan emoney tanpa harus bertransaksi langsung dan masih banyak manfaatnya seperti membayar BPJS, membeli token listrik serta membayar segala yang berkerjasama dengan aplikasi e-money itu sendiri.

Dari segi kelemahaan dan kelebihan e-money juga ada kelemahaan e-money yang jelas dan mendasar ialah karena memakai jarinagn internet secara otomatis data nasabah terancam dan juga uang yang di top up oleh nasabah bisa saja sewaktu waktu bisa hilang kesalahan oleh softwarenya sedangkan kelebihan dari e-money ialah kita tidak perlu membawa uang tunai,transaksi menjadi lebih akurat karena dikelola oleh komputer,kita juga tidak perlu menunggu uang kembalian karena kita membayar sesuai dengan harga,terdapat database yang dapat mencatat seluruh transaksi yang kita lakukan sehingga kita tidak akan lupa transaksi apa saja yang kita lakukan dan yang terpenting transaksi menjadi lebih cepat dan lebih praktis.

\section{Dampak E-money Terhadap Pedagang atau Pengusaha (Merchant)}

Pengusaha atau merchant dalam sistem e-money ini adalah pengusaha atau pedagang yang menyediakan penggunakan fasilitas jasa pembayaran dengan e-money dalam transaksi pembayarannya. Pengusaha dalam hal ini berupaya menyiapkan hal ini untuk meningkatkan efektifitas dan efisiensi usahanya. Dari sisi pengusaha, peningkatan konsumsi yang diikuti dengan efisiensi biaya transaksi akan meningkatkan profit bagi pengusaha yang kemudian berpotensi untuk mendorong aktivitas usaha dan eskpansi usaha. Semakin efisien biaya transaksi yang diperoleh dari penggunaan alat pembayaran non tunai semakin besar potensi peningkatan output. Hal ini pada gilirannya mendorong peningkatan produksi di sektor riil yang dapat mendorong pertumbuhan ekonomi. Sementara efisiensi yang terjadi dari penggunaan $e$ money bagi pengusaha adalah keamanan dalam tiap transaksi, dimana pengusaha tidak perlu khawatir akan adanya uang palsu dan saat transaksi selesai maka uang dari pembayaran akan masuk rekening pengusaha yang terhubung dengan transaksi

\section{KAJIAN PUSTAKA}

Aplikasi e-money adalah uang elektronik yang dapat di akses melalui aplikasi dan juga sebagai alat pembayaran yang menggunakan media elektronik. Berguna untuk melakukan pembayaran melalui sistem online dan juga memudahkan nasabah tanpa harus mengantri serta tidak memakan waktu yang lama. Aplikasi ini juga banyak kegunaan bukan hanya sebagai alat pembayaran tetapi juga sebagai alat untuk menabung tanpa harus menunggu lama di bank hanya perlu melakukan top-up dengan 
merchant yang telah bekerja sama selain itu juga aplikasi ini juga bisa sebagai alat transfer uang kita hanya perlu melakukan di ponsel kita tanpa harus mencari mesin atm.

Transaksi adalah suatu kegiatan yang dilakukan seseorang yang menimbulkan perubahan terhadap harta atau keuangan yang dipunyai baik itu bertambah ataupun berkurang. Sistem pembayaran adalah sistem yang mencakup aturan, lembaga dan mekanisme yang digunakan untuk melaksanakan pemindahan dana guna memenuhi suatu kewajiban yang timbul dari suatu kegiatan ekonomi. Transaksi juga suatu yang berkaitan dengan pembelian maupun penjualan dengan melakukan menukar barang dengan uang ataupun sebaliknya dan yang terpenting transaksi harus dilakukan dengan dua orang atau lebih.

Sistem keamanan adalah suatu sistem dimana menjamin keamanan data pada nasabah yang dirancang untuk melindungi dari sebuah ancaman dan juga memberikan proteksi pada suatu jaringan agar terhindar dari berbagai ancaman luar yang mampu merusak jaringan.

\section{METODE PENELITIAN}

Metode penelitian yang digunakan dalam penulisan ini adalah deskriptif kualitatif. Adapun penelitian deskriptif kualitatif ditujukan mengumpulkan informasi secara aktual dan terperinci sehingga tidak menjelaskan hubungan kausalitas maupun melakukan uji hipotesis.

\section{HASIL PENELITIAN}

Dalam aplikasi e-money ini masih banyak keraguan dari masyarakat karena belum menjamin kemanannya sebab aplikasi ini sewaktu -waktu bisa saja di hack oleh orang yang tidak bertanggung jawab maka dari itu masih banyak masyarakat yang lebih memilih transaksi yang offline karena lebih aman dan kita juga bertatap muka saat bertransaksi. Di dalam bertransaksi melalui ini sangat rentan dengan hack karena menggunakan jaringan internet, serta terdapat juga resiko yaitu data hilang karena kesalahan software dan juga masalah yang berat masih belum banyak merchant serta perusahaan yang menggunakan alat pembayaran yang berbasis online. Berikut ini adalah faktor resiko keamanan dalam penggunaan uang elektronik.

1. Pencurian

Bentuk kejahatan e-money ytang paling sederhana adalah melakukan pengisian dana secara tidak legal. Pencurian juga bisa dilakukan misalnya dengan cara mencuri kunci cryptographic tanpa sepengetahuan perusahaan

2. Duplication of devices

Membuat duplikat dari aplikasi yang dimiliki nasabah kejahatan ini cenderung sulit karena harus memiliki chip yang persis

3. Alteration or duplication of data/software

Kejahatan yang melalui upaya perubahan atau modifikasi data atau aplikasi yang ada pada kartu asli, sedemikian rupa sehingga pelaku memperoleh keuntungan finansial

4. Alteration of message

Resiko ini melalui upaya perubahan/intervensi ketika data elektronis/message dikirim, pada saat transaksi berlangsung. Potensi resiko lebih mungkin terjadi.

5. Penyangkalan transaksi (repudiation)

Penyalahgunaan lainnya dalam penyelenggaraan e-money adalah penyangkalan transaksi. Potensi resiko pada e-money berbasis software dan menggunakan pengiriman message saat transaksi melalui jaringan transaksi 
6. Malfunction

Dapat berupa data corrupt atau hilang, tidak berfungsinya aplikasi atau kegagalan dalam pengiriman message.

Sistem keamanan e-money dan e-wallet harus memiliki sistem keamanan yang kuat karena agar bisa mengurangi resiko dalam aplikasi karena resiko dalam aplikasi ini banyak seperti kehilangan dana sewaktu waktu dan juga takut kehilangan data nasabah akan disalahgunakan orang yang tidak bertanggung jawab. Maka dari itu seharusnya keamanan juga harus lebih siap jadi masyarakat yang akan membuka aplikasi menjadi lebih tenang dan juga aman karena sistem yang dimiliki.

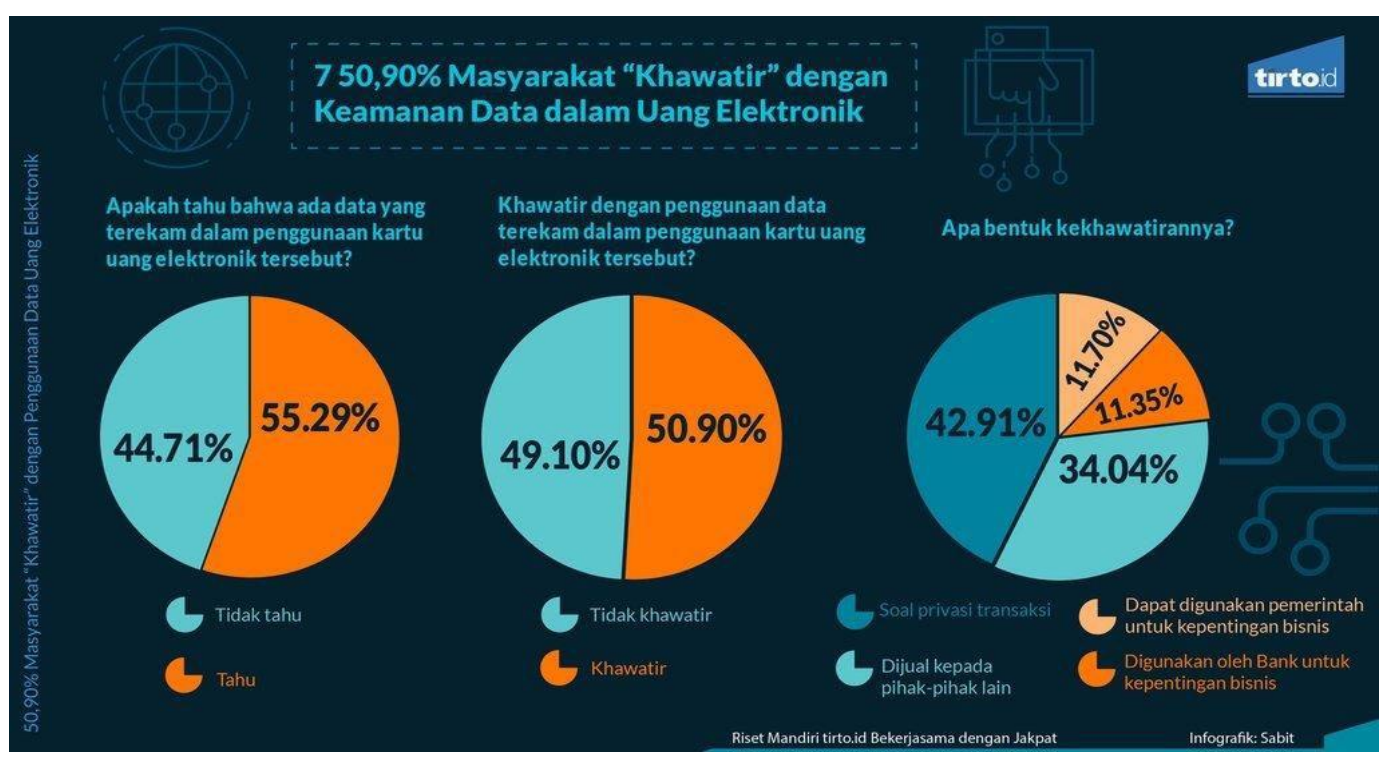

Gambar:tirto.id

Dari data diatas kita bisa menilai masyarakat masih ragu menggunkan e-money untuk kehidupan sehari harinya karena didasari ketakutan data nasabah yang bisa saja dipergunakan oleh orang yang tidak bertanggung jawab. Maka dari itu perusahaan yang memiliki aplikasi e-money harus benar benar terus memperbaiki sistem keamananya atau dengan cara pemilik perusahaan e-money di indonesia membuat satu program dimana data nasabah benar benar terjaga dan juga tidak ada resiko lain maka nasabah akan merasa nyaman dan tidak akan merasa ragu akan penggunaan aplikasi yang berbasis uang elektronik ini. Dan bagi pemilik perusahaan yang bekerja sama dengan aplikasi yang menggunakan pembayaran e-money itu merasa aman juga karena mereka juga akan merasakan imbasnya dengan adanya kejahatan ini.

\section{KESIMPULAN}

Aplikasi e-money dapat mempermudah customer dalam melakukan transaksi juga dapat mengefesiensikan waktunya yang bisa bertransaksi lewat ponsel dan juga tidak harus mendatangi tempat transaksi itu sendiri. Aplikasi ini juga menguntungkan pelaku bisni bukan hanya customer, pelaku bisnis dapat mengambil keuntungan dengan kerja sama dengan perusahaan aplikasi e-money ini dengan mendapatkan keuntungan dan juga dikenal masyarakat luas bisnis yang dimiliki serta bagi customer keuntungan yang di dapat juga banayak selain efesiensi waktu juga customer mendapatkan diskon-diskon menarik serta cashback yang diberikan oleh perusahaan aplikasi e-money ini selain itu 
terkadang aplikasi e-money ini memberikan hadiah-hadiah yang diundi agar mambuat masyarakat yang belum mempunyai akun berlomba-lomba membuat akun karena akan mendapatkan banyak keuntungan selain diskon dan cashback sebagai pengguna baru customer juga mengikuti undian. Bagi indonesia ini satu kemajuan yang signifikan karena masyarakatnya telah mengikuti teknologi terkini jadi pemerintah tidak harus memberikan pengenalan lebih lanjut karena masyarakat sudah mengenal aplikasi ini dengan sendirinya melalui ponselnya. 


\section{DAFTAR PUSAKA}

Fadillah fabi ferry. 2018 . Sudah Saatnya Beralih ke E-money, Alat Pembayaran Zaman Now

Katadata.co.id 2017. Ombudsman minta BI Berikan Jaminan Keamanan Saldo dalam E-Money

Abidin Sofyan Muhammad. DAMPAK KEBIJAKAN E-MONEY DI INDONESIA SEBAGAI ALAT SISTEM PEMBAYARAN BARU.

http://jurnalmahasiswa.unesa.ac.id/index.php/jurnal-akuntansi/article/download/13212/12129

Hidayat, et. al., 2006, Kajian Operasional E-money, Bank Indonesia

Direktorat Akuntansi dan Sistem Pembayaran Bank Indonesia, 2007, Kebijakan, Implementasi dan

Permasalahan APMK di Indonesia, Materi Presentasi dalam Forum Diskusi Penyusunan Kebijakan TI Terkait Implementasi APMK 